\title{
Reflections on My Two Years
}

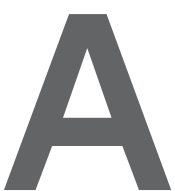

S MY TERM as ACM President draws to an end, I have been reflecting on my time serving our organization. It is easy to get lost in the dayto-day demands of this position, losing sight of what we have been able to accomplish during the past two years. We have accomplished a lot.

A clear highlight for me and for many was the $50^{\text {th }}$ Turing celebration last year. Honoring our Turing Laureates and bringing together so many who have profoundly shaped our field, the event featured panels on key topics in computing, all of which can be viewed at https:/www.acm.org/turingaward-50/video. There are many special moments to enjoy; moments that still make me smile when I think back.

Another highlight for me was the greater prominence of our early-to-midcareer technical award, renamed the ACM Prize in Computing. Reflecting its stature, ACM Prize recipients now join our Turing Laureates, along with the Fields Medalists, Abel Laureates, and Nevanlinna Prize recipients at the annual Heidelberg Laureate Forum (http://www.heidelberg-laureate-forum. org/) for a week of mentoring and technical exchanges with 200 early-career researchers.

As many of you know, I have been particularly focused on the need to nurture and learn from the next generation of computing professionalsthose who will emerge as the leaders of ACM and our profession in the years ahead. Just over a year ago, the ACM Future of Computing Academy was formed (http://www.acm-fca.org/), with the goal of empowering the next generation of computing researchers and practitioners. Contributions from this group have already made a mark on ACM, influencing our publication and education initiatives and shaping our thinking on how we can play a leading role in solving today's and tomorrow's most pressing problems.

During my term we also have been buffeted by a number of unforeseen political, social, and technical policy challenges. These included proposed restrictions on free and open scientific exchange and seemingly unending revelations of powerful leaders - in media, politics, business, and, yes, even technology-behaving in completely unacceptable ways. ACM, like all professional organizations, had the choice to either run from these issues or take strong positions consistent with our character. I am proud that in response we have issued our Open Conference policy supporting global scientific exchange, our policy against harassment at ACM activities, and our U.S. and European policy guidelines on Algorithmic Transparency and Accountability.

My candidate statement two years ago outlined a pressing need for rapidly identifying and supporting emerging technical research areas. ACM's reputation for technical quality remains without peer, but that does not mean we can rest on our laurels. To get a handle on this we have surveyed our technical leaders and conducted targeted workshops around the world to identify emerging technical trends. This large body of input is currently being summarized but I note here that in addition to new technical directions in computing, more interdisciplinary work and a strong focus on the ethics of technology development and use were recurring themes.

Approximately half of our global members are practitioners. ACM has identified ways in which we already provide significant value along with ways in which we could do more. The ACM Practitioner Board has been doing a great job driving multiple activities, including a steady stream of high-quality and highly attended technical webi- nars, additions to ACM's Distinguished Speaker series to reflect more practitioner interests, and using meetups and theme packs to provide information on topics such as blockchain and AI/ML.

Those who know me know my commitment to diversity and inclusion. My appointments to boards and committees have sought to reflect regional and gender diversity. The launch of a task force on Diversity and Inclusion will shed additional light on ways ACM can promote inclusive best practices in all we do. I have also worked to forge links with multiple national computing societies. ACM's sponsorship of the United Nations' initiative on AIfor Good (https:// www.itu.int/en/ITU-T/AI/2018/Pages/default.aspx) has expanded our influence within a multi-cultural, interdisciplinary community working to harness technology to address critical world problems.

As my term ends, I am pleased to say that ACM remains strong financially with talented volunteers and headquarters staff committed to serving the community. I have been continually impressed with the variety and depth of new initiatives created by our SIGs, board, and committees.

Finally, while it is gratifying to see the progress I mention, I am the first to admit that our work on these efforts is far from finished. I see ACM as a continual 'work in progress' as computing and our community evolves. In the future, I believe ACM will need to constantly reassess priorities and activities to ensure we remain vital to the global computing community. I encourage each of you to keep doing what you do so well, keeping ACM the premier global computing society.

\footnotetext{
Vicki L. Hanson (vlh@acm.org) is a Distinguished Professor in the B. Thomas Golisano College of Computing, Rochester Institute of Technology, Rochester NY, USA.

Copyright held by author.
} 